\title{
Protein Tyrosine Phosphatase-1B Negatively Impacts Host Defense against Pseudomonas aeruginosa Infection
}

Lei Yue, ${ }^{*}$ Zhongping Xie, ${ }^{*}$ Hua Li, ${ }^{*}$ Zheng Pang, ${ }^{\dagger}$ Robert D. Junkins, ${ }^{\dagger}$ Michel L. Tremblay, ${ }^{\ddagger}$ Xiaochun Chen,${ }^{\S}$ and Tong-Jun Lin ${ }^{* \dagger \oplus \pi} \|_{* *}$

From The Institute of Medical Biology,* Chinese Academy of Medical Sciences and Peking Union Medical College, Kunming, China; the Departments of Microbiology and Immunology, ${ }^{\dagger}$ Pediatrics, $"$ and Pathology, $"$ Dalhousie University, Halifax, Nova Scotia, Canada; the Department of Biochemistry, ${ }^{\ddagger}$ Goodman Cancer Research Centre, McGill University, Montréal, Quebec, Canada; the Department of Neurology, ${ }^{\S}$ The Affiliated Union Hospital, Fujian Medical University, Fuzhou, China; and the Beatrice Hunter Cancer Research Institute, ** Halifax, Nova Scotia, Canada

Accepted for publication January 5, 2016.

Address correspondence to Tong-Jun Lin, M.D., Ph.D. The Institute of Medical Biology, Chinese Academy of Medical Sciences and Peking Union Medical College, 935 Jiaoling Rd, Kunming, Yunnan, China 650118. E-mail: tongjun.lin@dal.ca.

\begin{abstract}
Pseudomonas aeruginosa is a major opportunistic pathogen in immune-compromised individuals. Mechanisms governing immune responses to $P$. aeruginosa infection remain incompletely defined. Herein, we demonstrate that protein tyrosine phosphatase-1B (PTP1B) is a critical negative regulator in $P$. aeruginosa infection. PTP1B-deficient mice display greatly enhanced bacterial clearance and reduced disease scores, which are accompanied by increased neutrophil infiltration and cytokine production. Interestingly, PTP1B deficiency mainly up-regulates the production of interferon-stimulated response elements-regulated cytokines and chemokines, including chemokine ligand 5 (regulated on activation normal T cell expressed and secreted), CXCL10 (interferon $\gamma$-inducible protein 10), and interferon- $\beta$ production. Further studies reveal that PTP1B deficiency leads to increased interferon regulatory factor 7 (IRF7) expression and activation. These findings demonstrate a novel regulatory mechanism of the immune response to $P$. aeruginosa infection through PTP1B-IRF7 interaction. This novel PTP1B-IRF7-interferon-stimulated response elements pathway may have broader implications in Toll-like receptor-mediated innate immunity. (Am J Pathol 2016, 186: 1234-1244; http://dx.doi.org/10.1016/j.ajpath.2016.01.005)
\end{abstract}

Pseudomonas aeruginosa is the predominant pathogen in immune-compromised individuals and cystic fibrosis patients. $^{1,2}$ Effective host defense against $P$. aeruginosa infection relies on the efficient production of cytokines and chemokines to mobilize immune cells. However, overproduction of these mediators leads to tissue damage and decline of lung function. ${ }^{3,4} \mathrm{~A}$ calculated immune response is central for the host for clearing bacteria without causing tissue damage. Mechanisms controlling $P$. aeruginosa-mediated inflammatory responses remain incompletely defined.

Phosphorylation and dephosphorylation are fundamental mechanisms in signaling. The coordinated actions of protein tyrosine kinases and protein tyrosine phosphatases (PTPs) determine the level of tyrosine phosphorylation in a reversible manner. In the human genome, there are 107 genes that encode PTPs ${ }^{5}$ and 90 genes that encode protein tyrosine kinases. ${ }^{6}$ Although approximately half of the 107
PTP genes have been described in immune cells, ${ }^{7}$ little is known about PTPs in $P$. aeruginosa lung infection.

PTPs are broadly divided into four classes. PTP1B belongs to the class I intracellular nonreceptor PTPs. PTP1B is a widely expressed $50-\mathrm{kDa}$ (435 amino acids) protein. ${ }^{8}$ Several PTP1B substrates have been identified. Cell surface protein tyrosine kinases that have been shown as PTP1B substrates include epidermal growth factor receptor, ${ }^{9}$ platelet-derived growth factor receptor, ${ }^{9}$ colonystimulating factor 1 receptor, ${ }^{10}$ insulin receptor, ${ }^{11}$ and insulin-like growth factor-1 receptor. ${ }^{12}$ The intracellular

Supported by Natural Science Foundation of China grant 81471564 (T.-J.L.), Natural Sciences and Engineering Research Council of Canada (T.-J.L.), Yunnan Natural Science Foundation grant 2013FZ135 (L.Y.), and Jeanne and Jean-Louis Levesque Chair in Cancer Research grant (M.L.T.). Disclosures: None declared. 
PTP1B substrates include the cytoplasmic protein tyrosine kinases, such as c-Src ${ }^{13}$ and JAK2, ${ }^{14}$ and the adaptor protein, p62Dok. ${ }^{15}$ Thus, PTP1B has been implicated in a wide range of cellular functions. ${ }^{16}$ Through regulation of insulin signaling, PTP1B has a prominent role in metabolism, leading to the development of PTP1B inhibitors for the treatment of type 2 diabetes and obesity. ${ }^{16}$ Through regulation of Jak/STAT, a role of PTP1B in regulating immune signaling is emerging. ${ }^{16}$ However, whether PTP1B contributes to host defense against bacterial infection in vivo has not been reported previously.

In this study, we found that PTP1B deficiency significantly promotes the clearance of $P$. aeruginosa from the lung of mice. In vivo, PTP1B deficiency enhances IRF7interferon (IFN)-stimulated response elements (ISRE) pathway activation and mainly up-regulates the production of ISRE-regulated cytokines and chemokines, including chemokine ligand (CCL) 5, CXCL10, and IFN- $\beta$ production. In contrast, PTP1B deficiency showed limited effects on NF- $\mathrm{B}$-regulated cytokines, such as tumor necrosis factor (TNF), IL-1 $\beta$, macrophage inflammatory protein (MIP)-2, and IL-6 in the lung. More important, PTP1B deficiency has no effect on epithelial permeability. Thus, blockade of PTP1B activity enhanced lung inflammatory response without damaging epithelial integrity. These findings position PTP1B as a critical regulator in $P$. aeruginosa infection through targeting the IRF7-ISRE pathway.

\section{Materials and Methods}

\section{Animals}

The PTP1B-deficient mice were originally provided by Michel L. Tremblay (McGill Cancer Centre, Montréal, QC, Canada). All animal protocols were approved by the University Committee on Laboratory Animals, Dalhousie University (Halifax, NS, Canada), in accordance with guidelines of the Canadian Council on Animal Care.

\section{Abs}

Antibodies (Abs) for IRF3 (sc-9082), IRF7 (sc-9083), IRF7 (sc-74471), actin (sc-1616), proliferating cell nuclear antigen (sc-7907), rabbit anti-goat $\operatorname{IgG}$ horseradish peroxidase (sc-2768), and goat anti-rabbit IgG horseradish peroxidase (sc-2004) were purchased from Santa Cruz Biotechnology (Dallas, TX). An Ab for PTP1B (07-088) was purchased from Millipore (Merck KGaA, Darmstadt, Germany).

\section{Bacterial Preparation}

Pseudomonas aeruginosa samples were cultured in LuriaBertani broth, as described previously. ${ }^{17}$ Briefly, suspension cultures were grown until reaching the early stationery phase. Bacteria were washed in phosphate buffer and resuspended in saline for in vivo experiments or phosphate-buffered saline for in vitro assays. Pseudomonas aeruginosa strain 8821 , used in cell culture assays, was killed using an antibiotic mixture $(50 \mathrm{U} / \mathrm{mL}$ penicillin, $50 \mathrm{U} /$ $\mathrm{mL}$ streptomycin, $100 \mathrm{mg} / \mathrm{mL}$ piperacillin, $100 \mathrm{mg} / \mathrm{mL}$ ceftazidime, and $200 \mathrm{mg} / \mathrm{mL}$ gentamicin).

\section{Lung Infection with $P$. aeruginosa, Collection of Lung} and BALF, Animal Survival, and Disease Scores

Pseudomonas aeruginosa strain 8821 (a gift of Ananda M. Chakrabarty, University of Illinois, Chicago, IL), a mucoid strain isolated from a cystic fibrosis patient, was used. ${ }^{18}$ Mice were infected intranasally with $1 \times 10^{7}$ colonyforming unit (CFU) P. aeruginosa for 4 hours, or $1 \times 10^{9}$ CFU for 24-hour infections. After 4 or 24 hours, bronchoalveolar lavage fluid (BALF) was obtained by lavaging the lung with $1 \mathrm{~mL}$ phosphate-buffered saline containing $100 \mu \mathrm{g} / \mathrm{mL}$ soybean trypsin inhibitor. The lung tissue was obtained for histology study, detection of cytokines, myeloperoxidase (MPO) assay, and bacterial CFU counting.

Lung tissue was homogenized in $50 \mathrm{mmol} / \mathrm{L}$ HEPES buffer (4 $\mu \mathrm{L} / \mathrm{mg}$ lung) containing $100 \mu \mathrm{g} / \mathrm{mL}$ soybean trypsin inhibitor. For counting bacterial CFUs, $10 \mu \mathrm{L}$ homogenate was plated onto an agar dish and incubated for 24 hours at $37^{\circ} \mathrm{C}$. The lung homogenate was centrifuged at $4^{\circ} \mathrm{C}$ for 20 minutes at $18,000 \times g$. The supernatant was stored at $-80^{\circ} \mathrm{C}$ for later cytokine analysis. The pellet was resuspended and homogenized in $0.5 \%$ cetyltrimethylammonium chloride ( $4 \mu \mathrm{L} / \mathrm{mg}$ lung) and centrifuged, as described above. The cleared supernatant was used for MPO assay.

BALF $(10 \mu \mathrm{L})$ was plated on an agar dish and incubated for 24 hours for CFU counting. For detection of cytokines and MPO activity, BALF was centrifuged at $1200 \times g$ for 5 minutes at $4{ }^{\circ} \mathrm{C}$. The supernatants were used for cytokine analysis. The pellets were resuspended in $1 \mathrm{~mL} \mathrm{NH}_{4} \mathrm{Cl}$ $(0.15 \mathrm{~mol} / \mathrm{L})$ and centrifuged as before to lyse red blood cells. The supernatants were discarded, and the pellets were resuspended in $0.5 \%$ cetyltrimethylammonium chloride ( $250 \mu \mathrm{L}$ per mouse) and then centrifuged. The cleared extracts were used for MPO assay.

To determine the animal survival and diseases, mice were infected intranasally with $1 \times 10^{9} \mathrm{CFU}$ per mouse. The disease scores were recorded for 10 days, according to the following disease scoring system: i) physical appearance (0 indicates normal, 1 indicates lack of grooming, 2 indicates rough hair coat, and 3 indicates very rough hair coat); ii) posture (0 indicates normal, 1 indicates sitting in hunched position, 2 indicates hunched posture, head resting on floor, 3 indicates lying prone on cage floor/unable to maintain upright posture); iii) activity/behavior ( 0 indicates normal, 1 indicates somewhat reduced/minor changes in behavior, 2 indicates above plus change in respiratory rate or effort, and 3 indicates moves only when stimulated); iv) appetite ( 0 indicates normal, 1 indicates reduced appetite, 2 indicates not eating since last check point, and 3 indicates not eating for last two check points); v) hydration ( 0 indicates normal, 1 indicates mildly dehydrated, 2 
indicates moderately dehydrated, and 3 indicates severely dehydrated); vi) body weight ( 0 indicates $<5 \%$ change from preinfection weight, 1 indicates $<10 \%$ weight change, 2 indicates $10 \%$ to $15 \%$ weight change, and 3 indicates $15 \%$ to $19 \%$ weight change); and vii) body temperature (ventral surface temperature $\left(0\right.$ indicates $33^{\circ} \mathrm{C}$ to $34^{\circ} \mathrm{C}, 1$ indicates $28^{\circ} \mathrm{C}$ to $32.5^{\circ} \mathrm{C}, 2$ indicates $25^{\circ} \mathrm{C}$ to $27.5^{\circ} \mathrm{C}$, and 3 indicates $<24.5^{\circ} \mathrm{C}$ ). Total possible score $=21$. Animals were euthanized when the score reached or was $>15$.

\section{Dendritic Cell Culture}

Mouse dendritic cells were obtained in vitro by growing bone marrow cells from the femurs, according to published protocol with minor modification. ${ }^{19}$ Briefly, bone marrow cells were cultured in RPMI 1640 medium supplemented with $10 \%$ fetal calf serum, $50 \mu \mathrm{mol} / \mathrm{L}$ 2-mercaptoethanol (2-ME), $100 \mathrm{U} / \mathrm{mL}$ penicillin, $100 \mu \mathrm{g} / \mathrm{mL}$ streptomycin, and $5 \%$ of conditioned medium from the cell line X-63 (kindly provided by Dr. Jun Wang, Dalhousie University, Halifax, NS, Canada) containing granulocyte-macrophage colony-stimulating factor. Media were changed every 2 to 3 days by replacing half initially, and then the full volume on subsequent days.

\section{Cytokine Production}

Concentrations of IL-1 $\beta$, TNF, IL-6, MIP-2, regulated on activation normal $\mathrm{T}$ cell expressed and secreted (RANTES), IP-10, and IFN- $\beta$ in the BALF and the lungs, and culture supernatants were determined by enzyme-linked immunosorbent assay, as described previously, ${ }^{17}$ using $\mathrm{Ab}$ pairs from R\&D Systems (Minneapolis, MN).

\section{MP0 Assay}

The MPO assay was used to determine the infiltration of neutrophils into the lungs of the mice, as described previously. ${ }^{20}$ Briefly, samples in duplicate $(75 \mu \mathrm{L})$ were mixed with equal volumes of the substrate $\left(3,3^{\prime}, 5,5^{\prime}\right.$-tetramethyl-benzidine dihydrochloride, $3 \mathrm{mmol} / \mathrm{L}$; resorcinol, $120 \mu \mathrm{mol} / \mathrm{L}$; and $\mathrm{H}_{2} \mathrm{O}_{2}$, $2.2 \mathrm{mmol} / \mathrm{L}$ ) for 2 minutes. The reaction was stopped by adding $150 \mu \mathrm{L}$ of $2 \mathrm{~mol} / \mathrm{L} \mathrm{H}_{2} \mathrm{SO}_{4}$. The OD was measured at $450 \mathrm{~nm}$.

\section{In Vivo Epithelial Permeability Measurement}

Evans Blue Dye was used to determine vascular and epithelial permeability in lungs of mice infected with $P$. aeruginosa, as described previously. ${ }^{21}$ Briefly, mice were intranasally infected with $P$. aeruginosa strain 8821 $\left(1 \times 10^{9}\right.$ CFU per mouse $)$ for 24 hours. Eighteen hours before sacrifice, mice were injected i.p. with $400 \mu \mathrm{L}$ of $0.5 \%$ Evans Blue Dye (Sigma-Aldrich, St. Louis, MO) in phosphate buffer solution. Twenty-four hours after infection, mice were sacrificed. The BALF and serum were collected at 24 hours after infection (hpi). Serum was diluted 1:20 in phosphate buffer solution. Dye leakage into the BALF was assessed and is presented as permeability index, which is the OD620 ratio of BALF to serum (1:20 dilution).

\section{Nuclear Extract Preparation and EMSA}

An electrophoretic mobility shift assay (EMSA) was performed, as previously described. ${ }^{22}$ Briefly, nuclear protein extracts were prepared using a nuclear extract kit (Active Motif, Carlsbad, CA), following the manufacturer's protocol. Probe labeling was accomplished by treatment with T4 kinase (Life Technologies, Burlington, ON, Canada) in the presence of ${ }^{32} \mathrm{P}$ adenosine triphosphate (Perkin Elmer, Waltham, MA). Labeled oligonucleotides were purified on a Sephadex G-25M column (GE Healthcare, Pittsburgh, PA). Nuclear protein $(10 \mu \mathrm{g})$ was added to a $10 \mu \mathrm{L}$ volume of binding buffer supplemented with $1 \mu \mathrm{g}$ poly-(dI-dC) (GE Healthcare) for 15 minutes at room temperature. Labeled double-stranded oligonucleotide was added to each reaction mixture that was incubated at room temperature for 30 minutes and separated by electrophoresis on a $6 \%$ polyacrylamide gel in $0.5 \times$ Tris-boric acid-EDTA buffer. Gels were vacuum dried and subjected to autoradiography. The following synthesized double-stranded oligonucleotides were used: ISRE-binding consensus sequence on mouse IFN- $\beta$ promoter, 5'-GAAAACTGAAAGGGAGAACTGAAA- $3^{\prime 23}$; and NF- $\kappa$ B consensus sequence on the IL- 6 promoter, $5^{\prime}$-AGTTGAGGGGACTTTCCCAGGC-3' (Promega, Madison, WI).

Luciferase Assay for ISRE Activities and Enzyme-Linked Immunosorbent Assay-Based Assay for IRF7

Bone marrow-derived dendritic cells $\left(4 \times 10^{6}\right.$ cells $)$ were cotransfected with pISRE-Luc plasmid (Stratagene, La Jolla, CA) and RL-TK plasmid (Promega) using the Amaxa Mouse Dendritic Cell Nucleofector Kit (VPA-1011) with the Amaxa Nucleofector Device (program Y-001), according to the manufacturer's protocol. After transfection, cells were allowed to recover for 24 hours at $37^{\circ} \mathrm{C}$. Cells were then challenged for 4 hours with live $P$. aeruginosa (multiplicity of infection, 10). Firefly and Renilla activities were sequentially quantified using a dual-luciferase reporter assay system (Promega) in a Veritas microplate luminometer (Turner Biosystems, Sunnyvale, CA), according to the manufacturer's protocol.

IRF7 activity was also determined using an enzymelinked immunosorbent assay-based assay (TransAM kit; Active Motif, Carlsbad, CA), according to the manufacturer's instruction.

\section{Western Blot Analysis and Scanning Densitometry}

Cell lysates (25 to $30 \mu \mathrm{g}$ ) were subjected to electrophoresis in $10 \%$ SDS polyacrylamide gels. Gels were transferred to a polyvinylidene difluoride membrane, blotted with primary and secondary Abs, as indicated, and detected by an electrochemiluminescence detection system (Western Lightning Plus-ECL; Perkin Elmer). Scanning 
A

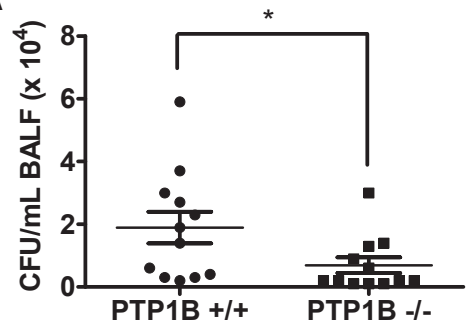

C

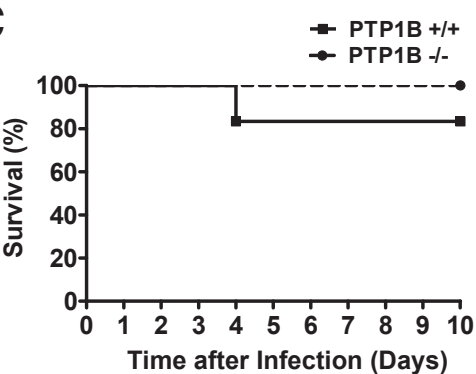

E

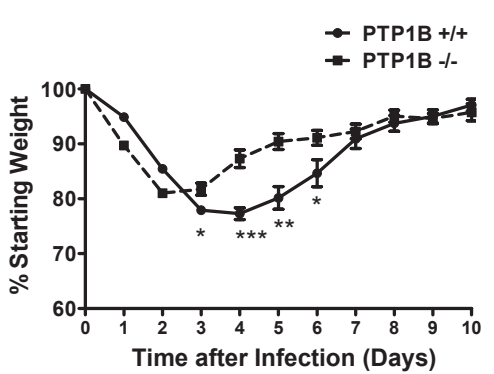

B

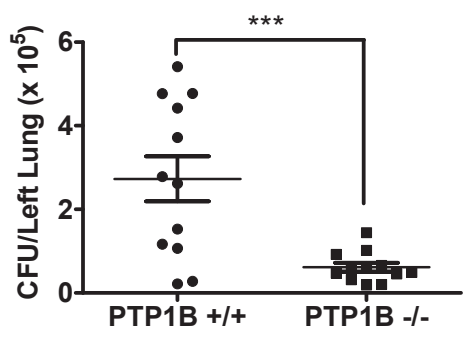

D

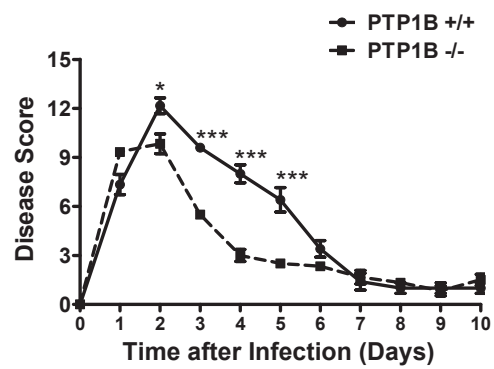

F

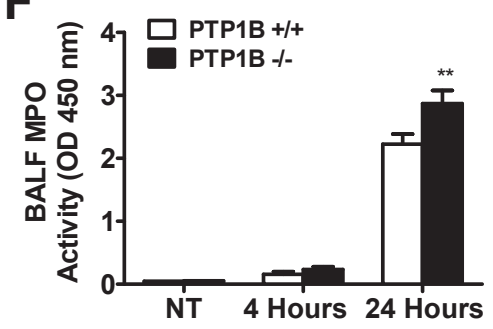

Figure 1 Protein tyrosine phosphatase1B (PTP1B) deficiency promotes bacterial clearance and neutrophil recruitment after Pseudomonas aeruginosa lung infection. Wild-type $(+/+)$ and PTP1B-deficient (-/-) mice were infected intranasally with $1 \times 10^{9}$ (24 hours) colony-forming units (CFUs) of $P$. aeruginosa strain 8821 or an equivalent volume of saline [not treated (NT)]. Lung and bronchoalveolar lavage fluid (BALF) were collected 4 or 24 hours after infection (hpi). Bacterial burden in the BALF (A) and lung (B) was assessed at $24 \mathrm{hpi}$. Animal survival (C), disease score (D), and body weight (E) were monitored for 10 days after infection. Neutrophil recruitment to the BALF $(\mathbf{F})$ and lung $(\mathbf{G})$ were assessed by myeloperoxidase (MP0) activity at 4 and $24 \mathrm{hpi}$. Data are given as means \pm SEM $(\mathbf{A}-\mathbf{G}) . n=10$ mice $(\mathbf{A}$ and $\mathbf{B}) ; n=6$ mice $(\mathbf{C}-\mathbf{E}) ; n=8$ mice $(\mathbf{F}$ and $\mathbf{G})$. ${ }^{*} P<0.05,{ }^{* *} P<0.01$, and ${ }^{* *} P<0.001$.

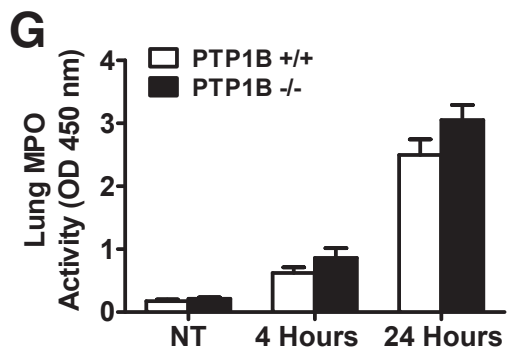

densitometry was performed using Scion Image (Scion, Frederick, MD).

\section{Statistical Analysis}

Data are presented as means \pm SEM of the indicated number of experiments. Statistical significance between multiple treatments was determined by one-way analysis of variance and post hoc Tukey's honest significance test. Alternatively, when two independent variables were analyzed, a two-way analysis of variance and a Bonferroni multiple-comparison test were used. Statistical analysis was performed using GraphPad Prism software version 5.04 (GraphPad Software Inc., La Jolla, CA). Differences were considered significant at $P<0.05$.

\section{Results}

\section{PTP1B Deficiency Promotes Bacterial Clearance and Neutrophil Recruitment after $P$. aeruginosa Lung Infection}

To determine the biological role of PTP1B in $P$. aeruginosa infection in vivo, PTP1B-deficient and wild-type mice were infected intranasally with $P$. aeruginosa strain 8821 . Bacterial burden was assessed in the lung and BALF of PTP1Bdeficient and wild-type mice at 24 hpi by CFU counting.
Significantly less bacteria were detected in the BALF (Figure 1A) and lungs (Figure 1B) of PTP1B-deficient mice compared with that of wild-type mice, suggesting that PTP1B-deficient mice are more efficient in clearing $P$. aeruginosa from the lung. Pseudomonas aeruginosa strain 8821 has less cytotoxic activity. No significant mortality was seen in both wild-type and PTP1B-deficient mice 10 days after infection (Figure 1C). In the initial 2 days after infection, PTP1B-deficient mice and wild-type mice showed similar disease scores and body weight loss. More important, PTP1B-deficient mice showed reduced disease scores (Figure 1D) and less body weight loss (Figure 1E) in the subsequent 3 days (day 3 to day 6 after infection). These findings suggest that PTP1B-deficient mice recover better from the $P$. aeruginosa infection. This is consistent with the better bacterial clearance capacity of PTP1Bdeficient mice.

Neutrophils contribute to the clearance of $P$. aeruginosa from the lungs. ${ }^{24,25}$ We next measured the infiltration of neutrophils into the respiratory tract after $P$. aeruginosa infection. Neutrophil infiltration was assessed using MPO as a neutrophil marker. ${ }^{20}$ Increased MPO level was seen in BALF of PTP1B-deficient mice after P. aeruginosa infection for 24 hours (Figure 1F). A similar trend of increased MPO activity was also seen in the lung at $24 \mathrm{hpi}$, although there was no 
statistical significance (Figure 1G). Data of the histological study of the lung appeared to be consistent with the MPO result, showing increased inflammatory cells in the airways of PTP1B-deficient mice at 24 hpi (Supplemental Figure S1).

\section{PTP1B Deficiency Leads to Enhanced Production of} Cytokines and Chemokines Regulated by the TRIF-IRFISRE Pathway without Damaging Epithelial Integrity

Next, we studied the potential mechanism involved in PTP1B-regulated immune responses. Several Toll-like receptors (TLRs) have been associated with $P$. aeruginosamediated immune responses in vitro and in vivo. ${ }^{26-33}$ To date, two major pathways have been described in TLR signaling, the transiently induced factor (TRIF)-IRF-ISRE pathway and the MyD88-IL-1 receptor associated kinase (IRAK)-NF-кB pathway. ${ }^{34,35}$ Previously, we reported that $P$. aeruginosa-mediated activation of the TRIF-IRF pathway regulates IFN- $\alpha / \beta$, CXCL10 (IP-10), and CCL5 (RANTES). ${ }^{17,36}$ In contrast, the MyD88-IRAK pathway regulates TNF, IL-1 $\beta$, and CXCL2 (MIP-2). ${ }^{22}$ First, we examined whether PTP1B affects IFN- $\alpha / \beta$, IP-10, and RANTES production in vivo.

PTP1B-deficient mice were infected with $P$. aeruginosa strain 8821 at the concentration of $1 \times 10^{7} \mathrm{CFU}$ per mouse for 4 hours or $1 \times 10^{9} \mathrm{CFU}$ per mouse for 24 hours. BALF and lung tissues were collected to determine IFN- $\beta$ (Figure 2, A and B), IP-10 (Figure 2, D and E), and RANTES (Figure 2, G and H). Pseudomonas aeruginosainduced IFN- $\beta$, IP-10, and RANTES production was significantly enhanced in PTP1B-deficient mice, suggesting an essential role of PTP1B in the regulation of these cytokines and chemokines in vivo. We further examined the mRNA expression by real-time quantitative PCR for IFN- $\beta$,
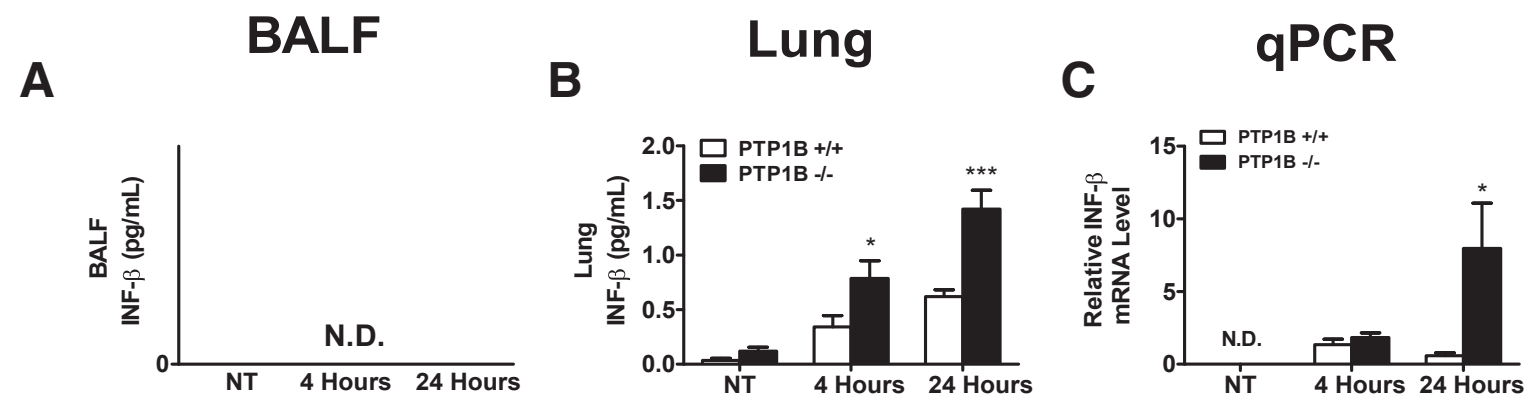

D

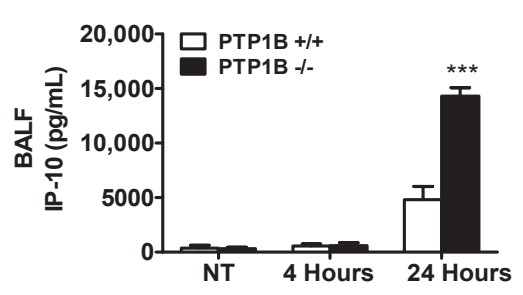

$\mathbf{G}$

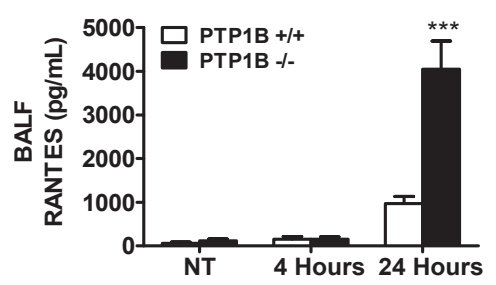

E

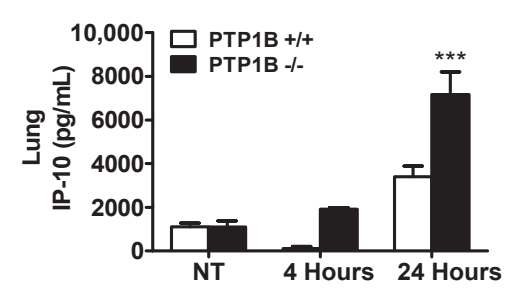

H

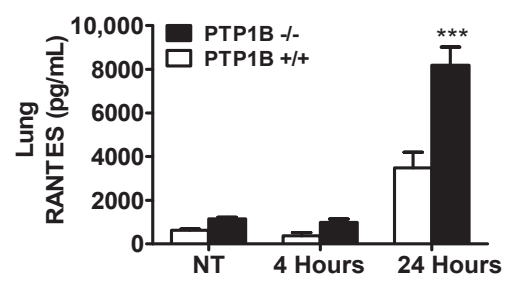

$\mathbf{F}$

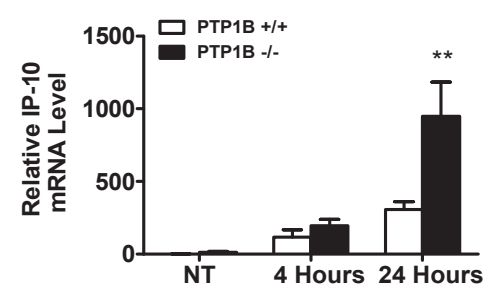

I

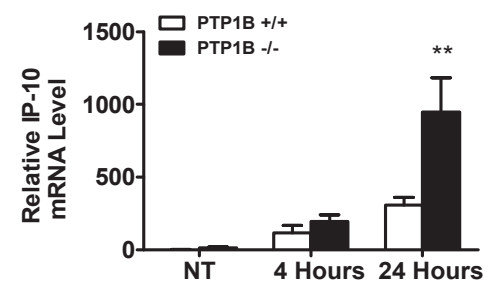

Figure 2 Protein tyrosine phosphatase-1B (PTP1B) deficiency promotes production of transiently induced factor (TRIF)-IRF-interferon (IFN)-stimulated response elements (ISRE)-regulated cytokines and chemokines after Pseudomonas aeruginosa lung infection. Wild-type $(+/+)$ and PTP1B-deficient $(-/-)$ mice were infected intranasally with $1 \times 10^{7}$ ( 4 hours) or $1 \times 10^{9}$ (24 hours) colony-forming units of $P$. aeruginosa strain 8821 or an equivalent volume of saline [not treated (NT)]. The bronchoalveolar lavage fluid (BALF) and lung were collected at 4 or 24 hours after infection. The production of IFN- $\beta$ (A-C), IP-10 (CXCL10; D-F), and regulated on activation normal T cell expressed and secreted (RANTES; chemokine ligand 5; G-I) was analyzed at the protein level in the BALF and lung by enzyme-linked immunosorbent assay and at the mRNA level in the lung by quantitative PCR. For the quantitative PCR analysis, IFN- $\beta$, IP-10, and RANTES expression was normalized by using hypoxanthine guanine phosphoribosyltransferase as an endogenous control. The average value of IP-10, and RANTES, in their individual NT group of wild-type mice (no $P$. aeruginosa infection in wild-type mice) was used as a calibrator to determine the relative levels of IP-10 and RANTES at different conditions. The average value of IFN- $\beta$ at 4 hours in wild-type mice ( $P$. aeruginosa infection in PTP1B wild-type mice at 4 hours) was used as a calibrator to determine the relative levels of IFN- $\beta$ at different conditions. Data are the means \pm SEM (A-I). $n=3$ to 6 mice per group (A-I). ${ }^{*} P<0.05,{ }^{*} P<0.01$, and ${ }^{* * *} P<0.001$ versus PTP1B ${ }^{+/+}$mice. ND, not determined. 
IP-10, and RANTES. Similarly, increased expression of IFN- $\beta$, IP-10, and RANTES mRNA was seen in the lungs of PTP1B-deficient mice after $P$. aeruginosa infection (Figure 2, C, F, and I).

IRF7 and IRF3 are master regulators of IFN- $\beta$, IP-10, and RANTES. $^{37}$ Interestingly, IRF7 mRNA, but not IRF3 mRNA, was up-regulated in the lung in PTP1B-deficient mice after $P$. aeruginosa infection (Figure 3). IRF7 induces transcription through activation of ISRE sites. Accordingly, we assessed the ISRE binding activity by performing EMSA on nuclear extracts prepared from the lungs of wild-type and PTP1B-deficient mice after $P$. aeruginosa (strain 8821) infection for 4 or 24 hours. The activity of ISRE binding was greatly enhanced in the lungs of PTP1B-deficient mice at 24 hpi (Figure 4, A and B). To confirm the specific IRF7-ISRE binding, supershift assay was performed using anti-IRF7 antibody. Anti-IRF7 Ab, but not IRF3 Ab, blocked ISRE site binding, supporting the IRF7-ISRE specific binding (Figure 4C). To further demonstrate PTP1B-regulated IRF7 activation, we used an enzyme-linked immunosorbent assay-based assay in which the plate was coated with specific IRF7 binding oligonucleotides. Nuclear proteins from mouse lungs were added to the plate. Consistent with the EMSA study, increased IRF7 activation was seen in PTP1B-deficient mice compared with wild-type mice at 24 hpi (Figure 4D).

IRF7 is a transcription factor that is translocated into the nucleus on activation. To confirm the regulation of IRF7 by PTP1B, nuclear proteins from the lungs of PTP1B-deficient mice and wild-type mice after $P$. aeruginosa infection were subjected to Western blot analysis. An increased IRF7 nucleoprotein level was seen in the lungs of PTP1Bdeficient mice at 24 hpi (Figure 4E).

These results reveal that the PTP1B is a potent negative regulator of the IRF7-ISRE-IFN- $\beta$ pathway in vivo.

Effective inflammatory response is required for host defense against bacterial infection. However, excessive inflammation has the potential of causing local tissue damages. To examine whether PTP1B affects airway epithelial integrity, Evans Blue Dye leakage into the airway was determined. As expected, $P$. aeruginosa infection increased dye leakage into the BALF, suggesting the effective inflammatory response to $P$. aeruginosa infection. Interestingly, there is no difference in permeability index between PTP1Bdeficient mice and wild-type mice (Supplemental Figure S2). Thus, increased inflammation because of PTP1B deficiency does not change epithelial permeability. These results suggest that blockade of PTP1B activity leads to effective inflammation without damaging epithelial integrity.

\section{PTP1B Deficiency Enhances the IRF-ISRE-IFN- $\beta$ Pathway Activation after $P$. aeruginosa Infection in Dendritic Cells in Vitro}

Dendritic cells actively contribute to the host defense against $P$. aeruginosa infection. ${ }^{38,39}$ Accordingly, dendritic
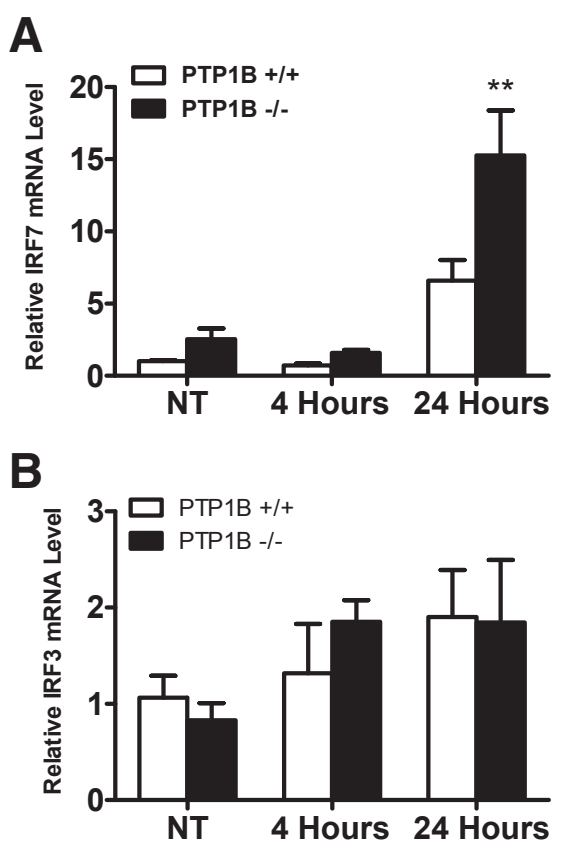

Figure 3 Protein tyrosine phosphatase-1B (PTP1B)-deficient mice display enhanced IRF7 transcription after Pseudomonas aeruginosa lung infection. Wild-type $(+/+)$ and PTP1B-deficient $(-/-)$ mice were infected intranasally with $1 \times 10^{7}$ ( 4 hours) or $1 \times 10^{9}$ (24 hours) colony-forming units of $P$. aeruginosa strain 8821 or an equivalent volume of saline [not treated (NT)]. Total RNA isolated from lung tissues was analyzed by real-time quantitative PCR for IRF7 (A) and IRF3 (B). IRF7 and IRF3 expression was normalized by using hypoxanthine guanine phosphoribosyltransferase as an endogenous control. The average value of IRF7 and IRF3 at the NT of wild-type (no $P$. aeruginosa infection in PTP1B wild-type mice) was used as a calibrator to determine the relative levels of IRF7 and IRF3 at different conditions. Data are the means \pm SEM (A and $\mathbf{B}) . n=4$ mice per group $(\mathbf{A}$ and $\mathbf{B}) .{ }^{* *} P<0.01$ versus $\mathrm{PTP} 1 \mathrm{~B}^{+/+}$ mice.

cells are used as a relevant cell type to demonstrate PTP1Bdependant IRF7-ISRE pathway activation in vitro. We assessed the innate immune response in PTP1B-deficient bone marrow-derived dendritic cells (BMDCs) infected by $P$. aeruginosa in vitro.

IRF7 induces transcription through activation of ISRE sites. To examine whether $P$. aeruginosa infection stimulates ISRE activity in dendritic cells, BMDCs were transfected with an ISRE luciferase plasmid and stimulated with $P$. aeruginosa (multiplicity of infection, 10) for 4 hours. Pseudomonas aeruginosa-induced ISRE activation was significantly increased in PTP1Bdeficient BMDCs compared with wild-type BMDCs (Figure 5A).

To assess the impact of PTP1B on cytokine production, wild-type and PTP1B-deficient BMDCs were exposed to $P$. aeruginosa (multiplicity of infection, 10) at different time points $(3,6,24$, and 48 hours). We tested the protein levels of cytokines or chemokines, including IFN- $\beta$, IP-10, and RANTES, which are mainly regulated by the IRF7/3-ISRE pathway. Consistent with in vivo 
A

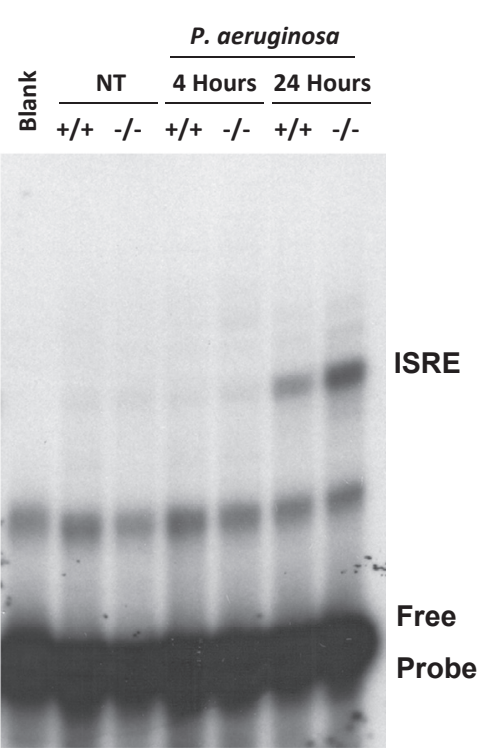

D

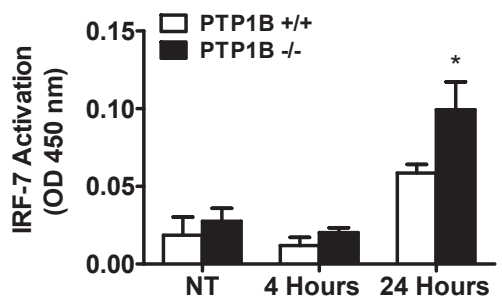

B

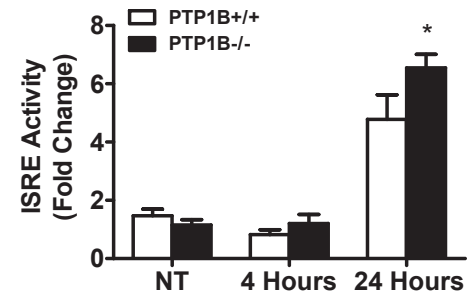

C

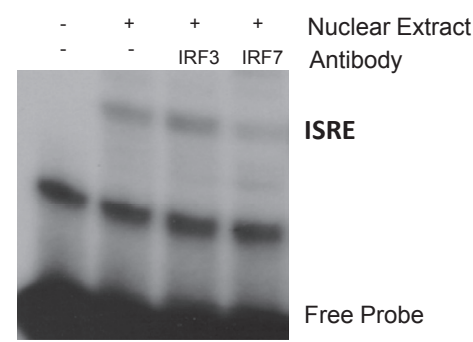

E

Lung

Nucleoprotein

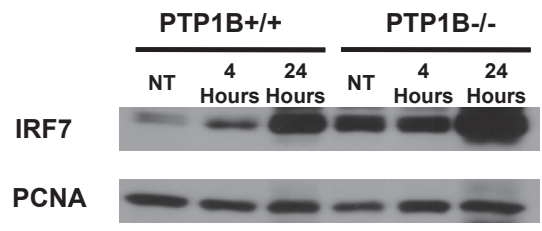

Figure 4 Protein tyrosine phosphatase-1B (PTP1B)-deficient mice display enhanced IRF7 activation after Pseudomonas aeruginosa lung infection. Wild-type $(+/+)$ and PTP1B-deficient $(-/-)$ mice were infected intranasally with $1 \times$ $10^{7}$ (4 hours) or $1 \times 10^{9}$ (24 hours) colonyforming units (CFUs) of $P$. aeruginosa strain 8821 or an equivalent volume of saline. A: Nuclear proteins were extracted from lung tissues obtained from individual mice and subjected to electrophoretic mobility shift assay (EMSA) by incubation with ${ }^{32}$ P-labeled interferon-stimulated response elements (ISRE) DNA probes. B: Transcription factor activity was quantified using scanning densitometry. C: Nuclear proteins from the lung of $\mathrm{PTP}_{1 \mathrm{~B}}{ }^{+/+}$mice treated with $1 \times 10^{9} \mathrm{CFU} P$. aeruginosa strain 8821 for 24 hours were incubated with or without specific antibody to IRF3 and IRF7 for 1 hour at room temperature before EMSA experiment using the ${ }^{32} \mathrm{P}$-labeled ISRE probe. D: IRF7 activity was determined using an ELISAbased assay. E: Nuclear proteins from PTP1B ${ }^{+/+}$ and PTP1 $\mathrm{B}^{-/-}$lung were subjected to Western blot analysis for IRF7. Proliferating cell nuclear antigen (PCNA) was used as control for nuclear protein loading. Blots are representative of three separate experiments. Data are given as means \pm SEM (B and D). $n=6$ (B); $n=3$ (D). ${ }^{*} P<0.05$. NT, not treated. experiments, the levels of IFN- $\beta$ and IP-10 were significantly enhanced in the supernatants of PTP1B-deficient BMDCs treated with $P$. aeruginosa compared with wild-type BMDCs (Figure 5, B and C). Interestingly, no significant differences of RANTES levels were observed between PTP1B-deficient and wild-type BMDCs (Figure 5D).

These results support the concept that PTP1B plays a selective negative regulatory role in the IRF7-ISRE-IFN- $\beta$ pathway during $P$. aeruginosa infection.
A

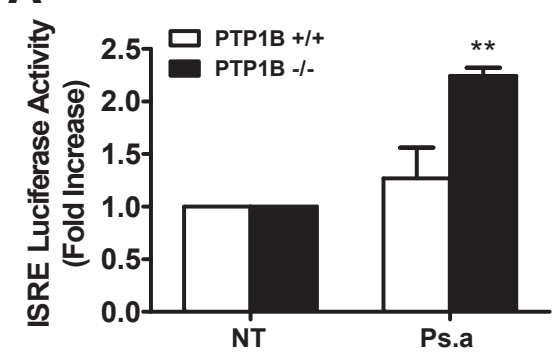

C

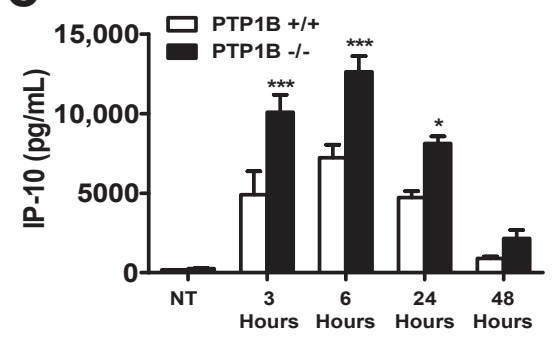

B

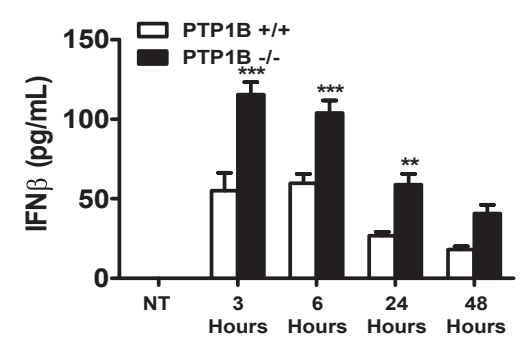

D

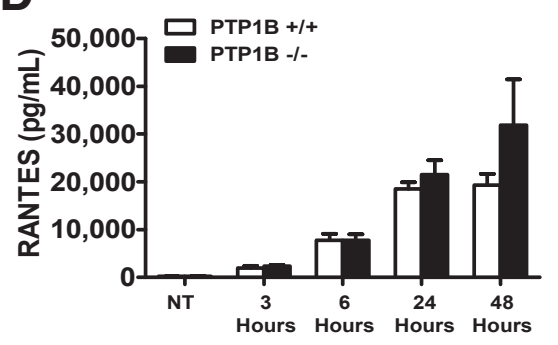

Figure 5 Protein tyrosine phosphatase-1B (PTP1B) promotes the IRF-interferon (IFN)stimulated response elements (ISRE) pathway activation after Pseudomonas aeruginosa infection and is physically associated with IRF7 in bone marrow-derived dendritic cells (BMDCs). A: Wildtype $(+/+)$ and PTP1B-deficient $(-/-)$ BMDCs were transfected with an ISRE luciferase reporter or control plasmids. Cells were stimulated for 4 hours with $P$. aeruginosa strain 8821 [multiplicity of infection (MOI), 1:10] or left untreated (NT). ISRE activity was measured relative to the control luminescence and presented as fold-increase compared with the NT group. B-D: Wild-type $(+/+)$ and PTP1B-deficient (-/-) BMDCs were NT or exposed to $P$. aeruginosa strain 8821 at an MOI of 1:10. Supernatants were collected at various time points and analyzed for the cytokines by enzyme-linked immunosorbent assay: IFN- $\beta$ (B), IP-10 (C), and regulated on activation normal $\mathrm{T}$ cell expressed and secreted (RANTES; D). Data are given as means \pm SEM $(\mathbf{A}-\mathbf{D}) . n=3$ (A-D). ${ }^{*} P<0.05,{ }^{* *} P<0.01$, and ${ }^{* *} P<0.001$ versus PTP1B ${ }^{+/+}$BMDCs. 
Increased NF- $\kappa$ B Activity in Vivo and Selectively

Enhanced Inflammatory Cytokine Production in PTP1B-

Deficient Mice or Dendritic Cell after $P$. aeruginosa

Infection

Previously, we reported that $P$. aeruginosa-mediated activation of the MyD88-IRAK-NF-KB pathway is largely responsible for TNF, IL-1 $\beta$, and CXCL2 (MIP-2) production. ${ }^{22}$ This is in contrast to IFN- $\alpha / \beta$, CXCL10 (IP-10), and CCL5 (RANTES), which are regulated by the TRIF-IRF pathway. ${ }^{17,36}$ Accordingly, a role of PTP1B on P. aeruginosamediated NF- $\kappa \mathrm{B}$ activation and TNF, IL-1 $\beta$, and CXCL2 (MIP-2) production was investigated.

PTP1B-deficient and wild-type mice were infected with $P$. aeruginosa strain 8821 for 4 or 24 hours. Nuclear extracts prepared from the lungs were used to examine NF- $\kappa \mathrm{B}$ activity by EMSA. The activity of NF- $\kappa \mathrm{B}$ was enhanced in the lungs of PTP1B-deficient mice at $24 \mathrm{hpi}$ (Figure 6). However, there are variable differences of TNF, IL-1 $\beta$, CXCL2 (MIP-2), and IL-6 between PTP1Bdeficient and wild-type mice in the BALF and lung (Figure 7). In the BALF, there is no difference of TNF, IL-1 $\beta$, and MIP-2 production between PTP1B-deficient and wild-type mice after $P$. aeruginosa infection for 4 or 24 hours. In the lung, there is no difference of TNF and IL-6 production between PTP1B-deficient and wild-type mice after $P$. aeruginosa infection for 4 or 24 hours. However, IL- $1 \beta$ and MIP-2 in the lung at the 24 hpi and IL-6 in the BALF at 4 hpi were increased in PTP1Bdeficient mice (Figure 7).

Bone marrow-derived dendritic cells were also used to examine the effect of PTP1B on $P$. aeruginosa-induced IL-6, TNF, IL-1 $\beta$, and MIP-2 production. No difference of $P$. aeruginos $a$-induced IL-1 $\beta$ production was found between PTP1B-deficient BMDCs and wild-type BMDCs. However, $P$. aeruginosa-induced IL-6, TNF, and MIP-2 was increased in PTP1B-deficient BMDCs (Supplemental Figure S3).

These results suggest that the $P$. aeruginosa-mediated NF- $\kappa$ B pathway is affected by PTP1B deficiency, but the effects of PTP1B on individual cytokines vary.

\section{Discussion}

Pseudomonas aeruginosa is a major cause of morbidity and mortality among cystic fibrosis and the immunecompromised patients. ${ }^{1,2}$ Several TLRs have been associated with $P$. aeruginosa-mediated immune responses. ${ }^{26-33}$ Two major pathways have been described in TLR signaling, the TRIF-IRF-ISRE and the MyD88-IRAK-NF- $\kappa$ B pathways. ${ }^{34,35}$ The TRIF-IRF pathway regulates IFN- $\alpha / \beta$, CCL5 (RANTES), and CXCL10 (IP-10) production. ${ }^{17,36}$ In contrast, the MyD88-IRAK pathway is largely responsible for TNF, IL-1 $\beta$, and CXCL2 (MIP-2) production. ${ }^{22}$ Previously, we demonstrated that both the TRIF-IRF-IFN
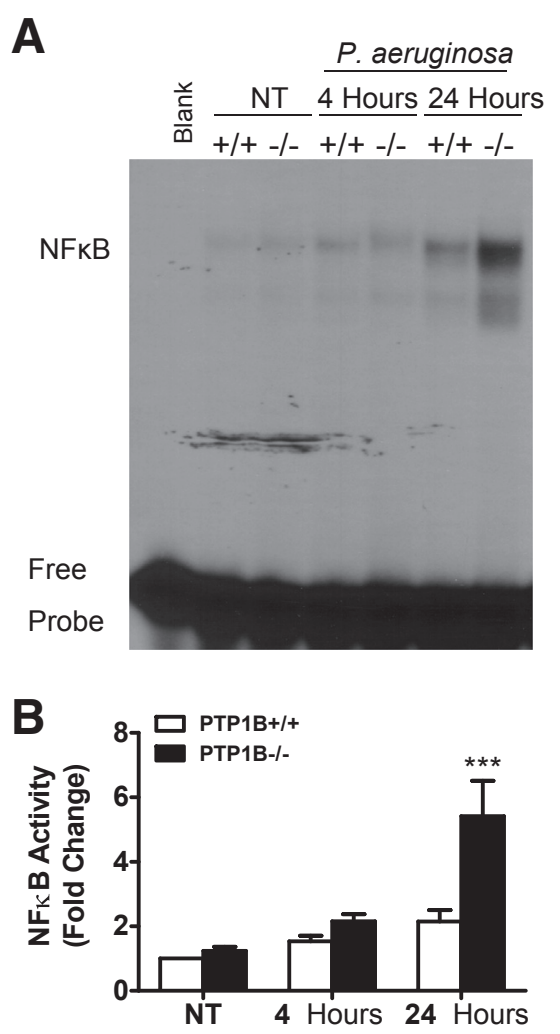

Figure 6 Protein tyrosine phosphatase-1B (PTP1B)-deficient mice display enhanced NF- $\kappa B$ activation after $P$. aeruginosa infection. Wild-type $(+/+)$ and PTP1B-deficient $(-/-)$ mice were infected intranasally with $1 \times 10^{7}$ (4 hours) or $1 \times 10^{9}$ (24 hours) colony-forming units of $P$. aeruginosa strain 8821 or an equivalent volume of saline [not treated (NT)]. A: Nuclear proteins were extracted from lung tissues obtained from individual mice and subjected to electrophoretic mobility shift assay by incubation with ${ }^{32}$ P-labeled NF-KB DNA probes. Data are representative of six individual experiments. B: Scanning densitometry was performed, and data are expressed as fold-change versus wild-type untreated lung. Data are given as means \pm SEM (B). $n=6$ (B). ${ }^{* * *} P<0.001$ versus wild-type $+/+$ mice.

pathway and the MyD88-IRAK-NF- $\mathrm{BB}$ pathway are integral components in the development of effective host defense against $P$. aeruginosa infection. ${ }^{17,22,36}$

More important, TLR-initiated activation signals are subsequently inhibited by negative signals that are required for immune cells to return to their basal resting condition. It has been recognized that TLRs induce the tyrosine phosphorylation of signaling molecules in response to bacterial infection. ${ }^{34,35}$ However, regulatory mechanisms involved in $P$. aeruginosa-mediated TLR signaling remain largely unknown. Herein, we showed that PTP1B preferentially regulates TRIF-IRF-IFN pathway activation. More important, deficiency of PTP1B leads to enhanced clearance of $P$. aeruginosa from the lung without damaging epithelial integrity. This positions PTP1B as a critical negative regulator affecting host defense against $P$. aeruginosa lung infection.

TLRs have been recognized as a central player in host defense against microbial infection. We provide strong 
A

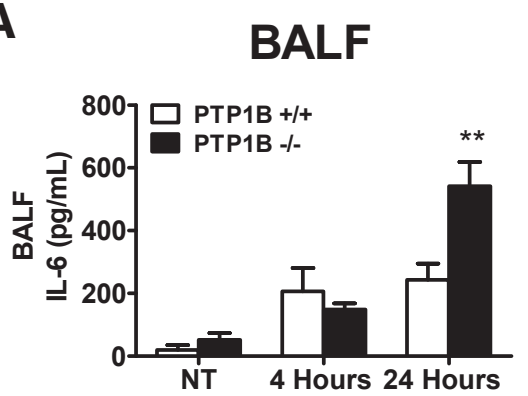

C

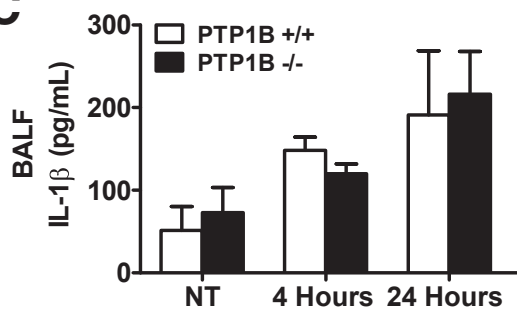

E

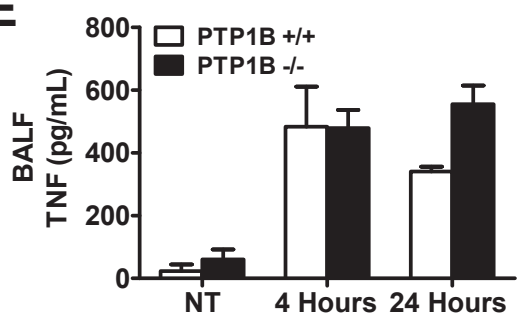

G

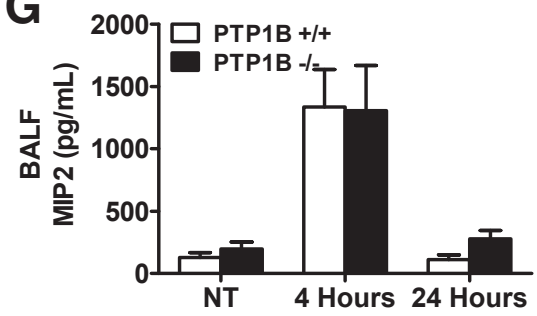

B
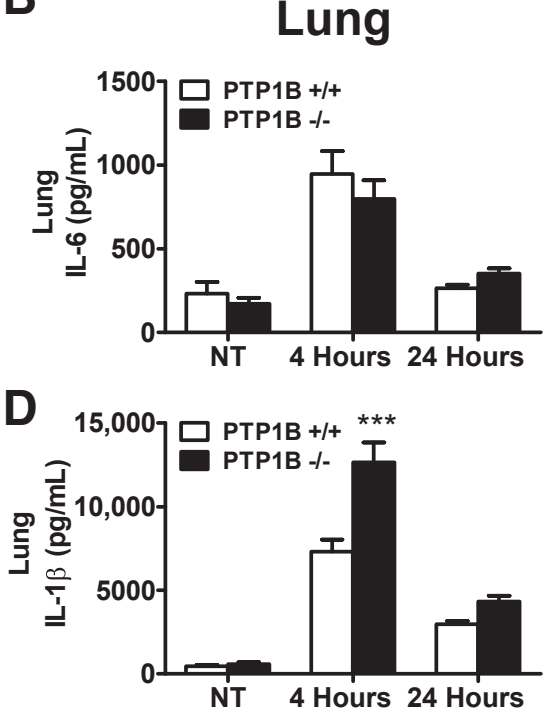

$\mathbf{F}$

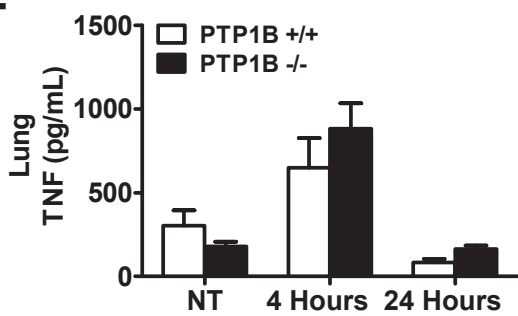

H

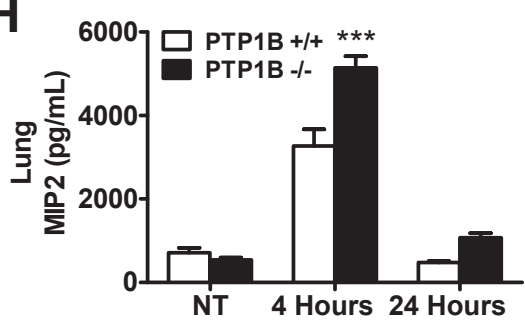

Figure 7 Effects of protein tyrosine phosphatase-1B (PTP1B) deficiency on NF- $\mathrm{KB}-$ regulated cytokines in the airways after Pseudomonas aeruginosa lung infection. Wild-type $(+/+)$ and PTP1B-deficient $(-/-)$ mice were infected intranasally with $1 \times 10^{7}$ (4 hours) or $1 \times 10^{9}$ (24 hours) colony-forming units of $P$. aeruginosa strain 8821 or an equivalent volume of saline [not treated (NT)]. Lung and bronchoalveolar lavage fluid (BALF) were collected 4 or 24 hours after infection. Supernatants were analyzed by enzyme-linked immunosorbent assay for IL-6 (A and B), IL-1B (C and D), tumor necrosis factor (TNF; $\mathbf{E}$ and $\mathbf{F}$ ), and macrophage inflammatory protein (MIP-2; $\mathbf{G}$ and $\mathbf{H}$ ). Data are given as means \pm SEM $(\mathbf{A}-\mathbf{H}) . n=8(\mathbf{A}-\mathbf{H})$. ${ }^{* *} P<0.01,{ }^{* * *} P<0.001$ versus wild-type mice. evidence showing that $P$. aeuginosa-mediated TLR signaling is negatively regulated by PTP1B. The identification of PTP1B in TLR signaling may have broad implications, considering the diverse roles of TLRs. The concept of PTP1B in the regulation of TLR signaling is consistent with a recent report showing that IRF7 mRNA (but not IRF3) was increased in PTP1B-deficient macrophages. ${ }^{40}$ Similarly, a previous report showed that ectopic expression of PTP1B in a macrophage cell line RAW cell decreased IFN- $\beta$ production by lipopolysaccharide (TLR4 ligand) or polyI:C (TLR3 ligand) stimulation or knockdown of PTP1B increased IFN- $\beta$ production by lipopolysaccharide or polyI:C. ${ }^{41}$

PTP1B deficiency is preferentially associated with IRF7mediated up-regulation of the production of CCL5, CXCL10, and IFN- $\beta$. This is an intriguing finding because the pattern of response is consistent with innate antiviral response. $^{42,43}$ This finding suggests that PTP1B might have a broader regulatory role in the host defense against bacterial and viral infections.

PTP1B deficiency also leads to increased NF- $\kappa$ B activation and enhanced IL-6 or MIP-2 production (both are mainly regulated by the MyD88-NF- $\kappa \mathrm{B}$ pathway ${ }^{22}$ ) after $P$. aeruginosa infection in vivo. Similarly, $P$. aeruginosainduced IL-6, TNF, and MIP-2 production by dendritic cells in vitro was also increased because of PTP1B deficiency. Others also reported that lipopolysaccharide- or polyI:Cinduced TNF and IL-6 production by RAW cells could be modulated by ectopic expression of PTP1B or knock-down of PTP1B. ${ }^{41}$ Thus, the NF- $\kappa$ B pathway appears also to be affected by PTP1B. This may be because of the fact that IRF7 directly interacts with MyD88 and TRAF6. ${ }^{44}$ In addition, IRF families often form different kinds of complex with other transcriptional factors or coactivators, such as NF- $\kappa$ B, STATs, I $\kappa$ B kinase $\alpha$, or calcium-binding protein, ${ }^{37,45}$ in the regulation of cytokine production. Increased 
IRF7 activation in the absence of PTP1B may enhance its

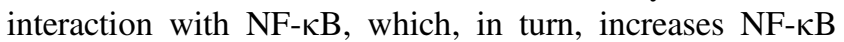
activation and the production of NF- $\kappa \mathrm{B}-$ regulated cytokines, such as IL-6, TNF, and MIP-2. However, we could not exclude the possibility that PTP1B may interact with additional targets upstream of NF- $\kappa \mathrm{B}$, considering that PTP1B has been found to have a wide range of substrates. ${ }^{16}$

The effect of PTP1B deficiency on the pattern of IRF7ISRE-regulated IFN- $\beta$ and IP-10 production after $P$. aeruginosa stimulation appears to be consistent in vivo and in vitro. However, the effect of PTP1B on the pattern of $P$. aeruginos $a-$ induced IL- 6 , TNF, and IL- $1 \beta$ production in dendritic cells in vitro, or in the BALF or lung in vivo, appears to be less consistent. This could be because of the fact that different cell types may respond to TLR stimulation differently. It has been recognized that, although dendritic cells, macrophages, endothelial cells, and synovial fibroblasts isolated from rheumatoid arthritis joint tissue all express TLR, they differ substantially in their response to TLR stimulation. ${ }^{46}$

The identification of PTP1B as a novel negative regulator of host defense against $P$. aeruginosa infection may have potential therapeutic implications, considering the intensive research on pharmacological PTP1B inhibitors. ${ }^{47}$ It is tempting to speculate that immune-compromised individuals or cystic fibrosis patients with persistent $P$. aeruginosa infection may benefit from inhibition of PTP1B by better clearance of $P$. aeruginosa from the lung. The PTP1B inhibitors may represent a promising avenue for preventing and treating $P$. aeruginosa infection. Targeting PTP1B for drug discovery is challenging because of the highly conserved and positively charged active-site pocket of the PTP1B molecule. ${ }^{48}$ PTP1B and T-cell protein tyrosine phosphatase share $74 \%$ homology in their catalytic domain, which could lead to off-target effects of PTP1B inhibitors. During the past decade, significant progress has been made in the development of potent and selective PTP1B inhibitors that engage both the active site and no catalytic sites. For example, targeting the disordered $\mathrm{C}$ terminus of PTP1B with an allosteric inhibitor appears to be promising. ${ }^{49}$ However, the success of PTP1B inhibitors in clinical use remains to be seen.

\section{Acknowledgments}

We thank Ananda M. Chakrabarty (University of Illinois, Chicago, IL) for providing the Pseudomonas aeruginosa strain 8821 and Dr. Jun Wang (Dalhousie University, Halifax, NS, Canada) for providing the X-63 cell line.

L.Y. and T.-J.L. conceived and designed the experiments. L.Y. performed the experiments; L.Y., Z.X., H.L., Z.P., R.D.J., X.C., and T.-J.L. analyzed the data; L.Y. and T.-J.L. wrote the paper; and M.L.T. contributed vital materials (protein tyrosine phosphatase-1B-deficient mice).

\section{Supplemental Data}

Supplemental material for this article can be found at http://dx.doi.org/10.1016/j.ajpath.2016.01.005.

\section{References}

1. Garau J, Gomez L: Pseudomonas aeruginosa pneumonia. Curr Opin Infect Dis 2003, 16:135-143

2. Cripps AW, Dunkley ML, Clancy RL, Kyd J: Pulmonary immunity to Pseudomonas aeruginosa. Immunol Cell Biol 1995, 73:418-424

3. Berger M: Inflammation in the lung in cystic fibrosis: a vicious cycle that does more harm than good? Clin Rev Allergy 1991, 9:119-142

4. Heeckeren A, Walenga R, Konstan MW, Bonfield T, Davis PB, Ferkol T: Excessive inflammatory response of cystic fibrosis mice to bronchopulmonary infection with Pseudomonas aeruginosa. J Clin Invest 1997, 100:2810-2815

5. Alonso A, Sasin J, Bottini N, Friedberg I, Osterman A, Godzik A, Hunter T, Dixon J, Mustelin T: Protein tyrosine phosphatases in the human genome. Cell 2004, 117:699-711

6. Manning G, Whyte DB, Martinez R, Hunter T, Sudarsanam S: The protein kinase complement of the human genome. Science 2002, 298: 1912-1934

7. Mustelin T, Vang T, Bottini N: Protein tyrosine phosphatases and the immune response. Nat Rev Immunol 2005, 5:43-57

8. Frangioni JV, Beahm PH, Shifrin V, Jost CA, Neel BG: The nontransmembrane tyrosine phosphatase PTP-1B localizes to the endoplasmic reticulum via its 35 amino acid C-terminal sequence. Cell 1992, 68:545-560

9. Haj FG, Verveer PJ, Squire A, Neel BG, Bastiaens PI: Imaging sites of receptor dephosphorylation by $\mathrm{PTP} 1 \mathrm{~B}$ on the surface of the endoplasmic reticulum. Science 2002, 295:1708-1711

10. Heinonen KM, Dube N, Bourdeau A, Lapp WS, Tremblay ML: Protein tyrosine phosphatase $1 \mathrm{~B}$ negatively regulates macrophage development through CSF-1 signaling. Proc Natl Acad Sci U S A 2006, $103: 2776-2781$

11. Cicirelli MF, Tonks NK, Diltz CD, Weiel JE, Fischer EH, Krebs EG: Microinjection of a protein-tyrosine-phosphatase inhibits insulin action in Xenopus oocytes. Proc Natl Acad Sci U S A 1990, 87: 5514-5518

12. Kenner KA, Anyanwu E, Olefsky JM, Kusari J: Protein-tyrosine phosphatase $1 \mathrm{~B}$ is a negative regulator of insulin- and insulin-like growth factor-I-stimulated signaling. J Biol Chem 1996, 271: 19810-19816

13. Bjorge JD, Pang A, Fujita DJ: Identification of protein-tyrosine phosphatase $1 \mathrm{~B}$ as the major tyrosine phosphatase activity capable of dephosphorylating and activating c-Src in several human breast cancer cell lines. J Biol Chem 2000, 275:41439-41446

14. Myers MP, Andersen JN, Cheng A, Tremblay ML, Horvath CM, Parisien JP, Salmeen A, Barford D, Tonks NK: TYK2 and JAK2 are substrates of protein-tyrosine phosphatase 1B. J Biol Chem 2001, 276: 47771-47774

15. Dube N, Cheng A, Tremblay ML: The role of protein tyrosine phosphatase 1B in Ras signaling. Proc Natl Acad Sci U S A 2004, 101: 1834-1839

16. Feldhammer M, Uetani N, Miranda-Saavedra D, Tremblay ML: PTP1B: a simple enzyme for a complex world. Crit Rev Biochem Mol Biol 2013, 48:430-445

17. Power MR, Li B, Yamamoto M, Akira S, Lin TJ: A role of Toll-IL-1 receptor domain-containing adaptor-inducing IFN-beta in the host response to Pseudomonas aeruginosa lung infection in mice. J Immunol 2007, 178:3170-3176

18. Kamath S, Kapatral V, Chakrabarty AM: Cellular function of elastase in Pseudomonas aeruginosa: role in the cleavage of nucleoside 
diphosphate kinase and in alginate synthesis. Mol Microbiol 1998, 30: 933-941

19. Lutz MB, Kukutsch N, Ogilvie AL, Rossner S, Koch F, Romani N, Schuler G: An advanced culture method for generating large quantities of highly pure dendritic cells from mouse bone marrow. J Immunol Methods 1999, 223:77-92

20. Schneider T, Issekutz AC: Quantitation of eosinophil and neutrophil infiltration into rat lung by specific assays for eosinophil peroxidase and myeloperoxidase: application in a brown Norway rat model of allergic pulmonary inflammation. J Immunol Methods 1996, 198:1-14

21. Junkins RD, Carrigan SO, Wu Z, Stadnyk AW, Cowley E, Issekutz T, Berman J, Lin TJ: Mast cells protect against Pseudomonas aeruginosainduced lung injury. Am J Pathol 2014, 184:2310-2321

22. Power MR, Peng Y, Maydanski E, Marshall JS, Lin TJ: The development of early host response to Pseudomonas aeruginosa lung infection is critically dependent on myeloid differentiation factor 88 in mice. J Biol Chem 2004, 279:49315-49322

23. Zhao W, Wang L, Zhang M, Wang P, Zhang L, Yuan C, Qi J, Qiao Y, Kuo PC, Gao C: Peroxisome proliferator-activated receptor gamma negatively regulates IFN-beta production in Toll-like receptor (TLR) 3and TLR4-stimulated macrophages by preventing interferon regulatory factor 3 binding to the IFN-beta promoter. J Biol Chem 2011, 286: $5519-5528$

24. Koh AY, Priebe GP, Ray C, Van Rooijen N, Pier GB: Inescapable need for neutrophils as mediators of cellular innate immunity to acute Pseudomonas aeruginosa pneumonia. Infect Immun 2009, 77: $5300-5310$

25. Drusano GL, Vanscoy B, Liu W, Fikes S, Brown D, Louie A: Saturability of granulocyte kill of Pseudomonas aeruginosa in a murine model of pneumonia. Antimicrob Agents Chemother 2011, 55: 2693-2695

26. Flo TH, Ryan L, Latz E, Takeuchi O, Monks BG, Lien E, Halaas O, Akira S, Skjak-Braek G, Golenbock DT, Espevik T: Involvement of toll-like receptor(TLR)2 and TLR4 in cell activation by mannuronic acid polymers. J Biol Chem 2002, 277:35489-35495

27. Hajjar AM, Ernst RK, Tsai JH, Wilson CB, Miller SI: Human Toll-like receptor 4 recognizes host-specific LPS modifications. Nat Immunol 2002, 3:354-359

28. Roger T, David J, Glauser MP, Calandra T: MIF regulates innate immune responses through modulation of Toll-like receptor 4. Nature 2001, 414:920-924

29. Vogels MT, Mensink EJ, Ye K, Boerman OC, Verschueren CM, Dinarello CA, van der Meer JW: Differential gene expression for IL-1 receptor antagonist, IL-1, and TNF receptors and IL-1 and TNF synthesis may explain IL-1-induced resistance to infection. J Immunol 1994, 153:5772-5780

30. Adamo R, Sokol S, Soong G, Gomez MI, Prince A: Pseudomonas aeruginosa flagella activate airway epithelial cells through asialoGM1 and toll-like receptor 2 as well as toll-like receptor 5. Am J Respir Cell Mol Biol 2004, 30:627-634

31. Lorenz E, Chemotti DC, Vandal K, Tessier PA: Toll-like receptor 2 represses nonpilus adhesin-induced signaling in acute infections with the Pseudomonas aeruginosa pilA mutant. Infect Immun 2004, 72: 4561-4569

32. Soong G, Reddy B, Sokol S, Adamo R, Prince A: TLR2 is mobilized into an apical lipid raft receptor complex to signal infection in airway epithelial cells. J Clin Invest 2004, 113:1482-1489

33. Jacchieri SG, Torquato R, Brentani RR: Structural study of binding of flagellin by Toll-like receptor 5. J Bacteriol 2003, 185:4243-4247
34. Liew FY, Xu D, Brint EK, O'Neill LA: Negative regulation of toll-like receptor-mediated immune responses. Nat Rev Immunol 2005, 5: 446-458

35. Takeda K, Akira S: TLR signaling pathways. Semin Immunol 2004, $16: 3-9$

36. Carrigan SO, Junkins R, Yang YJ, Macneil A, Richardson C, Johnston B, Lin TJ: IFN regulatory factor 3 contributes to the host response during Pseudomonas aeruginosa lung infection in mice. J Immunol 2010, 185:3602-3609

37. Honda K, Taniguchi T: IRFs: master regulators of signalling by Tolllike receptors and cytosolic pattern-recognition receptors. Nat Rev Immunol 2006, 6:644-658

38. Peluso L, de Luca C, Bozza S, Leonardi A, Giovannini G, Lavorgna A, De Rosa G, Mascolo M, Ortega De Luna L, Catania MR, Romani L, Rossano F: Protection against Pseudomonas aeruginosa lung infection in mice by recombinant OprF-pulsed dendritic cell immunization. BMC Microbiol 2010, 10:9

39. Mukae H, Urabe K, Yanagihara K, Ishimoto H, Sakamoto N, Ishii H, Nakayama S, Ishimatsu Y, Abe K, Shirai R, Kohno S: Low expression of T-cell co-stimulatory molecules in bone marrow-derived dendritic cells in a mouse model of chronic respiratory infection with Pseudomonas aeruginosa. Tohoku J Exp Med 2010, 220:59-65

40. Pike KA, Hutchins AP, Vinette V, Theberge JF, Sabbagh L, Tremblay ML, Miranda-Saavedra D: Protein tyrosine phosphatase 1B is a regulator of the interleukin-10-induced transcriptional program in macrophages. Sci Signal 2014, 7:ra43

41. Xu H, An H, Hou J, Han C, Wang P, Yu Y, Cao X: Phosphatase PTP1B negatively regulates MyD88- and TRIF-dependent proinflammatory cytokine and type I interferon production in TLR-triggered macrophages. Mol Immunol 2008, 45:3545-3552

42. Hagele H, Allam R, Pawar RD, Anders HJ: Double-stranded RNA activates type I interferon secretion in glomerular endothelial cells via retinoic acid-inducible gene (RIG)-1. Nephrol Dial Transplant 2009, 24:3312-3318

43. Julkunen I, Sareneva T, Pirhonen J, Ronni T, Melen K, Matikainen S: Molecular pathogenesis of influenza A virus infection and virusinduced regulation of cytokine gene expression. Cytokine Growth Factor Rev 2001, 12:171-180

44. Kawai T, Sato S, Ishii KJ, Coban C, Hemmi H, Yamamoto M, Terai K, Matsuda M, Inoue J, Uematsu S, Takeuchi O, Akira S: Interferonalpha induction through Toll-like receptors involves a direct interaction of IRF7 with MyD88 and TRAF6. Nat Immunol 2004, 5:1061-1068

45. Sobhkhez M, Skjesol A, Thomassen E, Tollersrud LG, Iliev DB, Sun B, Robertsen B, Jorgensen JB: Structural and functional characterization of salmon STAT1, STAT2 and IRF9 homologs sheds light on interferon signaling in teleosts. FEBS Open Bio 2014, 4:858-871

46. Lundberg AM, Drexler SK, Monaco C, Williams LM, Sacre SM, Feldmann M, Foxwell BM: Key differences in TLR3/poly I:C signaling and cytokine induction by human primary cells: a phenomenon absent from murine cell systems. Blood 2007, 110:3245-3252

47. Zhang S, Zhang ZY: PTP1B as a drug target: recent developments in PTP1B inhibitor discovery. Drug Discov Today 2007, 12:373-381

48. Barr AJ: Protein tyrosine phosphatases as drug targets: strategies and challenges of inhibitor development. Future Med Chem 2010, 2 : $1563-1576$

49. Krishnan N, Koveal D, Miller DH, Xue B, Akshinthala SD, Kragelj J, Jensen MR, Gauss CM, Page R, Blackledge M, Muthuswamy SK, Peti W, Tonks NK: Targeting the disordered C terminus of PTP1B with an allosteric inhibitor. Nat Chem Biol 2014, 10:558-566 